\title{
ə‘"What's Up with the Weather?" Public Engagement with Extreme Event Attribution in the United Kingdom $\mathscr{O}$
}

\author{
Joshua Ettinger, ${ }^{\mathrm{a}}$ Peter Walton, ${ }^{\mathrm{b}} \mathrm{J}_{\text {Ames Painter }},{ }^{\mathrm{c}}$ Shannon Osaka, ${ }^{\mathrm{a}}$ And Friederike E. L. Otto ${ }^{\mathrm{b}}$ \\ ${ }^{\text {a }}$ School of Geography and the Environment, University of Oxford, Oxford, United Kingdom \\ ${ }^{\mathrm{b}}$ Environmental Change Institute, University of Oxford, Oxford, United Kingdom \\ ${ }^{\mathrm{c}}$ Reuters Institute for the Study of Journalism, Department of Politics and International Relations, University of Oxford,
} Oxford, United Kingdom

(Manuscript received 5 November 2020, in final form 22 February 2021)

\begin{abstract}
The science of extreme event attribution (EEA) - which connects specific extreme weather events with anthropogenic climate change-could prove useful for engaging the public about climate change. However, there is limited empirical research examining EEA as a climate change communication tool. To help fill this gap, we conducted focus groups with members of the U.K. public to explore benefits and challenges of utilizing EEA results in climate change advocacy messages. Testing a range of verbal and visual approaches for communicating EEA, we found that EEA shows significant promise for climate change communication because of its ability to connect novel, attention-grabbing, and event-specific scientific information to personal experiences and observations of extreme events. Communication challenges include adequately capturing nuances around extreme weather risks, vulnerability, adaptation, and disaster risk reduction; expressing scientific uncertainty without undermining accessibility of key findings; and difficulties interpreting mathematical aspects of EEA results. On the basis of our findings, we provide recommendations to help address these challenges when communicating EEA results beyond the climate science community. We conclude that EEA can help catalyze important dialogues about the links between extreme weather and human-driven climate change.
\end{abstract}

KEYWORDS: Adaptation; Uncertainty; Extreme events; Climate change; Communications/decision making

\section{Introduction and literature review}

Weather is one of the fundamental ways humans engage with, and make sense of, the physical environment. Spanning religious interpretations to scientific understandings, cultures around the world have sought to explain, predict, and, in some cases, control the weather (Hulme 2017; Endfield and Veale 2018). Weather is a universally relatable phenomenon, inspiring a quip often attributed to Oscar Wilde: "conversation about the weather is the last refuge of the unimaginative" (Jackson 2017). However, researchers are increasingly exploring how the weather might prove more valuable than just a conversation starter. As climate change continues to influence the frequency and severity of different kinds of weather extremes around the world [Intergovernmental Panel on Climate Change (IPCC) 2018], some researchers have hypothesized that extreme weather events might serve as "teachable moments" that could counter the abstract qualities or psychological distance of climate change (Wallace 2012; Halperin and Walton 2018; Zanocco et al. 2019).

Denotes content that is immediately available upon publication as open access.

Supplemental information related to this paper is available at the Journals Online website: https://doi.org/10.1175/WCAS-D-200155.s1.

Corresponding author: Joshua Ettinger, joshua.ettinger@ouce. ox.ac.uk
This notion relates to construal-level theory, which considers how individual engagement with an object or event can be shaped by spatial, temporal, social, and uncertainty perceptions (Bar-Anan et al. 2006; Jones et al. 2017). According to this perspective, by virtue of its tangible, visceral, and localized impacts, extreme weather could act as a wake-up call or "sentinel" of climate change that makes risks more visible and concrete, stimulating stronger support for climate action (Hamblyn 2009; Rudiak-Gould 2013).

A growing body of research has therefore sought to examine how extreme weather events might shape public engagement with climate change in terms of attitudes (e.g., Spence et al. 2011), beliefs (e.g., Whitmarsh 2008), and, in more limited studies, behavior (e.g., Hazlett and Mildenberger 2020). Researchers have particularly focused on the role of direct extreme weather experiences in shaping public opinion about climate change (e.g., Akerlof et al. 2013; Albright and Crow 2015; Demski et al. 2017). A meta-analysis by P. D. Howe et al. (2019) examined 73 studies exploring potential relationships between extreme weather experience and climate change perceptions. Although significant differences in study methodologies limited comparisons, they found mixed results: some studies suggest that weather experiences can increase climate change attention (salience) and beliefs (e.g., Spence et al. 2011; van der Linden 2014), but the extent of these effects may change over time (Hamilton and Stampone 2013; Konisky et al. 2016). Other studies find no measurable impact of extreme weather experiences on climate change perceptions (e.g., Whitmarsh 2008; Mildenberger and Leiserowitz 2017; Sun and Han 2018).

Aligned with observations across the broader science communication literature, studies examining public engagement 
with extreme weather have noted the role of contextual sociocultural factors and psychological dynamics in shaping how individuals interpret relations between weather events and anthropogenic climate change (Borick and Rabe 2017). A cognitive bias known as "motivated reasoning" can lead individuals to process information in ways that support preexisting beliefs (Reser et al. 2014) and the "availability heuristic" can lead individuals to assign more importance to topics that are more easily brought to mind (Redelmeier and Ng 2020). For example, it has been found that individuals express stronger beliefs about global warming when asked about the issue on days with warmer temperatures outside ( $\mathrm{Li}$ et al. 2011). The "social amplification of risk" framework likewise explores how sociocultural factors can play an important role in shaping risk perceptions (Kasperson et al. 1988). Media attention can also influence how long an event remains at the forefront of public awareness (Massumi 2011).

In terms of climate change and extreme weather, Ogunbode et al. (2019) found that prior climate change beliefs and political views influenced whether members of the public attributed U.K. floods in the winter of 2013/14 to climate change. Boudet et al. (2020) studied 15 U.S. communities that experienced extreme weather between 2012 and 2015 and concluded that a variety of factors influenced dialogues about climate change after the event, including educational levels, political views, as well as the scientific understanding of links between the kind of event and climate change. Zanocco et al. 2019, p. 363) noted a similar process occurring among members of the public, stating, "If policymakers and scholars are looking to turn extreme weather events into teachable moments, the educational window appears to be context dependent."

Smith and Jenkins (2013) point out, however, that extreme weather might be able to transcend political divisions and other individual ideological barriers by focusing on bipartisan matters of concern (i.e., harm from weather). Recent surveys indicate that belief in global warming among Americans is at a record high and researchers suspect that extreme weather is a significant factor behind this shift (Schwartz 2019; Leiserowitz et al. 2020). Importantly, the extent to which an individual or institution connects an individual weather event to climate change can also be a strategic political decision, which Lahsen et al. (2020) refer to as the "politics of disaster framings." As noted by Sarewitz (2011), rather than necessarily determining climate policies, climate science can become enmeshed in political processes.

Although studying potential climate change attitude, belief, and behavior shifts in the wake of direct extreme weather experience merits continued examination, more proactive communication efforts for engaging the public on connections between climate change and extreme weather are comparatively underresearched. In other words, beyond examining if the public draws their own perceived connections between extreme weather events and climate change, educational campaigns could help facilitate an understanding of these links. Indeed, climate activist groups frequently utilize extreme weather events as opportunities for public outreach and calls for climate action (e.g., Earthjustice 2019). Similarly, there is growing research on the role of television weathercasters as climate change communicators and educators (Maibach et al. 2016; Feygina et al. 2020). Such public engagement initiatives are liable to the cognitive biases described above, including motivated reasoning and confirmation bias. Dixon et al. (2019) demonstrated this, finding that messages highlighting the ways in which climate change influences different types of weather extremes triggered resistance in audiences skeptical of climate change.

As noted by Ogunbode et al. (2019, p. 38), "Public engagement efforts could be significantly aided by placing scientific evidence of the connection between extreme weather and climate change, where available, at the fore of climate change communication." Yet a long-standing challenge of using extreme weather as a communication tool is that despite a firm scientific basis concerning the physical principles of how climate change can influence different kinds of extreme weather events, the connections between human-induced climate change and specific weather events have crucial nuances; every weather event always has many different drivers, and the damages wrought by such events depend on who-and what-is in harm's way. Moreover, there are longstanding critiques around the framing of natural hazards as "natural disasters" that belie the role of human decision-making in shaping vulnerability to extreme events (Chmutina and von Meding 2019; Kelman 2020). It can be misleading to overstate the role of climate change and portray it as the sole cause of sudden-onset weather events or their resulting damages. Climate science can generally only demonstrate how climate change has altered the probability and/or magnitude of such events (and in some cases, to a very large degree Ciavarella et al. 2020), among other factors. Scientists and science communicators have therefore relied on metaphors to help explain the changing climate-weather relationship such as "loaded dice," in which climate change increases the odds of extreme events happening (Hansen et al. 2012), or state that "this is the sort of event that we expect to become more likely as a result of climate change" (Painter et al. 2020).

However, the scientific capabilities to understand how climate change affects specific weather events have recently evolved (Otto 2017). Since Allen (2003) initially proposed calculating the changing risk of extreme weather events due to climate change, climate scientists have developed techniques to estimate the extent to which human-driven climate change has influenced recent weather extremes, which is known as extreme event attribution (EEA) or probabilistic event attribution (National Academies of Sciences Engineering and Medicine 2016). There are two main methods to EEA: a likelihood-based approach in which scientists explore how climate change altered the likelihood and/or intensity of an event occurring by comparing models of our planet today and counterfactual worlds with different levels of anthropogenic greenhouse gas emissions, and another approach in which scientists explore whether climate change was a necessary condition for an event to develop (Easterling et al. 2016). This paper focuses on the likelihood approach as it is more widely applied in international contexts. For example, the research group World Weather Attribution found that climate change made the 2019-20 Australian bushfires at least 30\% more likely to have 
occurred (van Oldenborgh et al. 2020) and the 2020 heat wave in Siberia at least 600 times more likely to have occurred (Ciavarella et al. 2020).

The robustness of attribution analyses depends primarily on three factors: quality of weather observations, ability of climate models to accurately simulate weather, and a strong scientific basis concerning the relationship of atmospheric processes and climate change (Marjanac et al. 2017). Scientific confidence in the results varies across different types of extreme weather. Heat and cold extremes, for example, are generally simpler to attribute, whereas wildfires and tropical and extratropical cyclones are more difficult (National Academies of Sciences, Engineering, and Medicine 2016). Currently, the evidence available from attribution research is strongly biased toward high-income countries, associated with a lack of high-quality observational data and research capacity-a situation researchers are trying to rectify (Otto et al. 2020). Nevertheless, EEA offers a significantly more granular perspective of how climate change influences specific extreme events that moves beyond general descriptions of meteorological relationships. This study focuses exclusively on potential communication applications of EEA, rather than methodological aspects and debates around the science of attributing of extreme events to anthropogenic influences. We acknowledge the importance of these debates but note that our study, by virtue of its aims and methods, is not positioned to address these issues.

The attribution field itself is rapidly growing with an increasing number of studies each year and significant media interest (Painter and Hassol 2020; Pidcock et al. 2020). Scholars continue to explore potential applications of attribution, including the development of climate loss and damage policy mechanisms (James et al. 2014), climate litigation (Marjanac et al. 2017; Minnerop and Otto 2020), and climate adaptation planning (Hulme et al. 2011; Betts 2021). Researchers are also increasingly exploring how attribution results are reported in the media (Osaka et al. 2020; Painter et al. 2020). Yet despite ongoing interest in attribution's potential applications, there has been limited exploration of attribution from a public engagement perspective, although its potential communication value is frequently pointed out (e.g., Stott and Walton 2013; Messling et al. 2015; Sippel et al. 2015; National Academies of Sciences, Engineering, and Medicine 2016). By quantifying climate change's effect on a specific weather event, attribution studies could make the risks of climate change less abstract, going beyond descriptions of general meteorological relationships between global warming and weather. EEA focuses on actual observed events, which differs from other types of climate science projections that are not explicitly linked to real-world experiences and subject to uncertainties around emission trajectories and changes in future vulnerability/exposure.

Sippel et al. (2015) found that representatives of environmental organizations felt attribution could prove helpful for their public campaigns and communications. Yet communicating attribution presents significant challenges and risks. Osaka and Bellamy (2020) conducted interviews and focus groups with scientists, journalists, policy makers, farmers, and environmentalists in order to examine reactions to attribution studies of the 2011-17 California drought. They found that focus group participants experienced difficulties understanding scientific uncertainty associated with EEA and tended to doubt the rigor of the science when presented with a range of attribution studies of the same event. Similar to studies of extreme weather perceptions described above, they also found that attribution results are subject to a motivated reasoning process in which individuals assess the accuracy of EEA based on their preexisting views about climate change. Others have expressed concerns that attribution's focus on the changing risk of a meteorological hazard could detract from considerations of other societal dynamics associated with the impacts of weather events, including adaptation, exposure, and vulnerability (Hulme et al. 2011; Janković and Schultz 2017). Lusk (2020) argues that using attribution as a public communication tool could lead to detrimental misunderstandings of climate science. He describes how EEA might lead audiences to erroneously believe climate change directly causes extreme weather events, rather than altering an event's likelihood or magnitude. To avoid misunderstandings of climate science and causality, Lusk suggests climate change messages focus on the broader change in risk of weather events types, rather than an assessment of human-induced climate change's influence upon a specific event.

Aligned with these communication issues, there is growing guidance on how to effectively communicate links between climate change and extreme weather. Hassol et al. (2016) offer communication principles for climate scientists to more effectively share their findings, including using phrases such as "a range" rather than "uncertainty." Lewis et al. (2019) suggest communicating attribution results using calibrated language and levels of confidence in a similar manner as IPCC reports. Seeking to move toward a more participatory communication model, other researchers have experimented with games and "spinner boards" to portray how climate change can influence extreme weather events (Parker et al. 2016; Dryden and Morgan 2020). Among gray literature, the organization Practical Action tested EEA communication approaches in Kenya and India, examining responses to different wording choices and visuals to describe probability, intensity, frequency, and uncertainty dimensions of EEA (Budimir and Brown 2017). They found that local decision-makers, media officials, and members of the public responded differently to particular word choices and visuals used to describe EEA results, suggesting a more tailored communication approach. The organization Climate Outreach suggests that messages related to extreme weather and climate change should go beyond the science by tapping into shared values and human dimensions, such as community solidarity and resilience in the aftermath of disaster (Marshall 2014).

Given the growing volume of EEA studies, as well as continued development toward the operationalization of EEA to provide rapid information on potential links between climate change and extreme events shortly after they occur (Copernicus 2019), there remains a need for further insights into communication aspects of EEA. As stated in the U.S. National Academies review of attribution (National Academies of Sciences, Engineering, and Medicine 2016, p. 25), "a careful 
and comprehensive treatment of the many issues associated with science communication related to climate attribution could be a study in its own right." It is therefore timely to further explore how nonclimate scientists respond to EEA findings and in what ways EEA can be beneficial, neutral, or detrimental as a climate change communication tool. This qualitative study is guided by two key research questions:

1) What are the benefits and challenges of communicating EEA findings with nonclimate scientists in order to promote stronger public engagement with climate change?

2) How can strategic word choices and data visualizations enable greater understanding and stronger engagement with EEA findings among nonclimate scientists?

\section{Methods and materials}

In this study, we explored responses to recent EEA results among nonclimate scientists based in the county of Oxfordshire, United Kingdom. A focus group approach was selected as it can facilitate a deep exploration of attitudes and meaning-making processes around a particular topic, as well as guide the development of products and programs (Krueger and Casey 2000). Although focus groups are not statistically representative of a population, they can offer rich, in-depth data on the reasons why individuals respond in particular ways to information. Additionally, given the prominence of conversations about the weather in cultural life, a focus group approach helped incorporate the role of social exchange and dialogue in shaping views on the attribution of weather events to climate change. Participants were recruited through advertisements in Oxfordshire community social media groups, resident associations, sports clubs, university groups, and snowball sampling procedures.

Because of the coronavirus, the focus groups were held via online video chat. Given that focus groups are traditionally held in person, two pilot focus groups were conducted. From these tests, we ascertained that a slightly smaller group size than is typically advised for focus groups $-3-5$ participants, as opposed to 6-8 (Bloor et al. 2001) —would enable more fluid and natural discussions online. Smaller focus groups are also not unprecedented and are actually preferred by some researchers in certain contexts (Morgan 1996; Bloor et al. 2001). Rather than a single large group, we therefore opted for a larger quantity of smaller focus groups. Four online focus groups with 4,3,3, and 3 participants, respectively, were held in summer 2020. Each focus group lasted between 70 and $90 \mathrm{~min}$. Recordings of the focus group sessions were transcribed, anonymized, and analyzed in NVivo by the lead author using a deductive content analysis to group themes according to our research questions, including the categories of communication benefits and communication challenges (research question 1), as well as considerations for accessible communication (research question 2). An inductive approach was used to code and organize statements falling within these categories (Bengtsson 2016). This study's online supplemental information provides the full list of codes used in the analysis.
An important limitation of this study's sample is that all participants reported a high or extremely high level of climate change concern prior to their participation (demographic characteristics of the participants are available in the online supplemental material). This may reflect characteristics of the U.K. population, which, according to recent polling, is exhibiting increased levels of concern about climate change (Capstick et al. 2019). It may also be associated with the recruitment process in which individuals passionate about environmental issues are more likely to register for an environmentally themed focus group. We determined that informed consent procedures required potential participants to know that the focus group concerned an environmental topic, but participants were not aware of the specific EEA focus. Given that the key research objective is to explore responses of nonclimate scientists to EEA, rather than test the efficacy of EEA as a persuasive device for reaching individuals skeptical or dismissive of climate change, the composition of the groups remains valid for the purposes of this study.

Upon joining the call and after introductions, participants read a short text that briefly explained EEA and highlighted several recent attribution findings showing a climate change influence on the likelihood or magnitude of extreme events around the world. Participants were then asked to respond to a series of open-ended questions exploring a broad range of reactions to the material, such as to what extent the information aligned, altered, or conflicted with their beliefs about climate change; to what extent they understood EEA results; and any other reflections they had about the material. Following a product development focus group approach (Krueger and Casey 2000), participants were then presented with language and visual options for describing EEA results (see the online supplemental material) and asked to discuss their opinions. The verbal phrasings were compiled based on a systematic review of the ways in which attribution findings have been typically reported in publications of the World Weather Attribution research group (World Weather Attribution 2020), with additional input from climate scientists who conduct these attribution analyses, as well as prior literature on EEA communication (Budimir and Brown 2017). Visual representations were selected based on a review of prior visuals used in World Weather Attribution group publications, from Lewis et al. (2019), as well as from the website www.datavizproject.com, which provides a comprehensive list of data visualization approaches. The selection of the visuals was guided by three criteria:

1) Suitability: Visuals should be appropriate for depicting EEA results (i.e., able to express a change in likelihood/intensity of a meteorological event).

2) Clarity: Visuals should be engaging and accurate, while also not overly technical.

3) Replicability: Visuals should not be so complex that a scientist or science communication officer would have difficulty creating it.

These criteria were used to identify five visuals for focus group testing. The visuals included an icon and number chart, an icon 
and number chart including emoji faces to test icons that are more playful and relatable, a pictorial unit chart to express event frequency, an angular gauge based on Lewis et al. (2019), and a linear process diagram describing how attribution results fit in a broader meteorological context in which climate change influences extreme events (all visuals can be seen in the online supplemental material). We also included a boxplot to test how participants would respond to a data visualization taken directly from an academic publication. All text and visuals were tested using results from an EEA study of the U.K. 2019 summer heat wave (Vautard et al. 2019), specifically Oxfordregional data. The study was selected because of its local relevance to the participants.

\section{Results}

\section{a. Benefits of communicating EEA with the public}

Twelve of the 13 participants felt that EEA can be useful for climate change communication by connecting scientific data to personal experiences and observations of extreme weather events. "People who see it [extreme weather] portrayed on the news and the media quietly wonder, 'is this because of climate change?' and if that's a question the attribution studies can help to answer, then that's a good thing." There was a sense that EEA findings can demonstrate that climate change is not just a future threat and that it is happening here and now. "It's interesting that in the early days this has always [been a] theoretical possibility that will happen in the future and as time has gone past, it's become more and more [clear that it's] actually happening right now. So it becomes more stark and the numbers are helpful to reinforce that."

Beyond describing general meteorological relationships between climate change and extreme weather events, 9 of the 13 participants felt that providing a specific number on how climate change may have influenced an event was more persuasive and attention-grabbing than a more general description of how climate change relates to the event. "I think it shows ... that you are being exact and that you're not making it up." Another participant noted: "Instead of being like 'oh, this will affect this or whatever' and deniers or people might say you're just talking out of your ass, you can actually say 'well, here's this."' Several participants alluded to advertisements in which products are marketed using technical statistics that are not well understood by the public, but nevertheless make a product appear more robust from a marketing perspective. "I do think it [an EEA finding] does resonate with people. I mean when you look at a lot of products like shampoo, you know, it will say '4 times shinier'... it's used a lot in advertising and provided it's simple, I think it can hook more into the way people think."

Eight of the 13 participants reported that comparisons of today with the past and details about what the future holds for extreme weather events were helpful for understanding the impacts of climate change. The notion of comparing counterfactual worlds particularly stuck out to some participants. One participant alluded to the novel The Little Prince, in which the main character visits alternate worlds. Some felt strong emotional impacts from these imaginative comparisons. "I think it was having the parallels between two worlds, we are missing out on a world that's healthy and thriving and I feel quite angry about that." While they did not distrust the overall EEA technique, some participants questioned how accurately scientists could model a world without greenhouse gases. Seven of the 13 participants expressed a general appreciation that climate science was advancing: "I think it's important, I don't think it's irrelevant or redundant or anything. I think it kind of gives you more context and accuracy to the things you already believe." About half of the participants felt that EEA provided further validation of their climate change beliefs. One participant described her reaction as "vindication ... I guess because it's more proof.",

\section{b. Challenges of communicating EEA with the public}

All participants were emphatic that audience characteristics would significantly shape reactions to EEA findings and that EEA results would be much more accessible to those with a scientific background. The notion of changing likelihood was described as a "strange concept for people." Cultural differences were also discussed. For example, some findings, such as an increase in the temperature and frequency of heat waves, could be perceived as a positive effect. As one participant described, "Why are these people complaining? It's lovely ... but I get it, it's not normal." No participants made any distinctions concerning the changing risks of hazards due to climate change and the roles of adaptation measures and disaster risk reduction in reducing vulnerability and exposure to extreme events. The focus group conversations focused exclusively on mitigation as the key action required to respond to changing extreme weather events associated with climate change. Participants discussed ways of reducing their individual greenhouse gas emissions by flying less and changing their modes of transportation, but they did not mention ways they or others could prepare for or adapt to extreme events (with the exception of air conditioning).

All participants felt that any expression of scientific uncertainty was unnecessary and confusing. "It's really, really tricky for just normal people unless you are just really studying this." Although participants seemed to recognize that this information can be relevant in certain contexts, all four focus groups discussed how the inclusion of uncertainty made their engagement with EEA more challenging and could undermine the public's confidence in the EEA results. "I understand from a scientific point of view you can't say it is this number [i.e., provide a single result without uncertainty] but for a person that don't [sic] have scientific literacy at all ... it's like you don't know what you're doing."

\section{c. EEA verbal and numerical framings}

Although some participants suggested that large percentages to describe a change in risk (e.g., "the Oxford 2019 heat wave was made $300 \%$ more likely") could provide shock value to capture attention, most participants (10/13) found the "X times more likely" framing easier to understand. Increasing likelihood "by a factor of $\mathrm{X}$ " was generally perceived as too academic and wordy. Likewise, most participants $(11 / 13)$ were in favor of the term "intensity" or "strength" 
rather than "magnitude" to describe the severity of weather events. Magnitude was perceived as too academic and disconnected from everyday language. Participants held contrasting views about the terms "'likelihood," "risk," "'odds," "chances," and "probability." It was generally agreed that probability was, like the term "magnitude," too divorced from everyday language, but participants debated the merits of the other terms. Likelihood was found to be the simplest, but some participants thought odds and chances would be more familiar to the general public. All participants found the phrase "return time" to describe extreme weather frequency unclear. However, many in principle saw value in learning how the frequency of a weather event changed. Given the participants' overall position against the inclusion of uncertainty for a public audience, they did not express clear support for any of the particular options for communicating uncertainty.

\section{d. EEA visuals}

No EEA visual was preferred across the focus groups, but participants unanimously disliked the usage of a boxplot to portray EEA results because it was generally not understood and was disengaging. One participant described it as "clinical." All focus groups felt that symbols and icons were engaging but warned that communicators should be careful with their utilization. For example, the usage of a sun as a symbol for a heat wave was perceived with positive emotions by some participants, reminding them of sunny weather forecasts, which they felt could undermine the risks of a heat wave. Participants closely scrutinized the colors and sizes of the icons, expressing a wide range of diverse views and picking up on numerous details. Emoji icons testing the role of more playful communications received mixed responses. Some participants felt they undermined the seriousness of the topic, describing them as "juvenile" or "patronizing," in the sense that the science was simplified too much. Others thought it made the data more relatable by connecting to human experiences of weather (e.g., an emoji with a red face in response to hot temperatures): "it's actually got some emotion and some experience in here." The gauge chart representing EEA results was generally familiar and comprehensible to participants, but participants in all focus groups warned against unintended consequences. In the case of the Oxford 2019 summer heat wave, the gauge only pointed to "more likely," which was one category away from no effect from climate change, giving the impression that the impact of climate change was negligible.

\section{e. Other findings}

Three of the 13 participants had heard of EEA or about an EEA result prior to participating in the study. All participants agreed that specific word choices and visuals used to describe EEA results made a significant difference in how they engaged with the data. Several participants noted that the size of the EEA finding itself mattered significantly in shaping their reactions. For instance, this study utilized the example of the U.K. 2019 summer heat wave (made 4 times more likely in Oxford), whereas showing participants the recent finding that climate change made the 2020 Siberian heat wave 600 times more likely might have evoked different responses (Ciavarella et al. 2020). As one participant described, “It wasn't shocking enough. I think maybe if it said like 17 times or like 100 times more likely, I would have been like, wow, but three or four times didn't really make an impact on me." Another participant noted: "it's about how people evaluate the size of these numbers for their own life." Three of the four focus groups discussed how human stories and local consequences could more effectively demonstrate the impacts of heightened risks of extreme weather. "Just saying that as a weather event occurs more or less likely kind of thing, so what? But if you start tying it to people's lives, $\mathrm{X}$ number of people will have died, $X$ number of people will have been admitted to the ER for breathing difficulty, then it starts to become human doesn't it?",

Most participants (10/13) supported the provision of broader context to EEA results with information about meteorological processes (i.e., how global warming makes heat waves more frequent and powerful) as well as the impacts of a more likely/intense weather event. EEA results, on their own, can be "a bit isolated. If you give a series of steps-oh well, I know why we're getting this-so giving a context can be useful.", Seven of the 13 of the participants reported that they experienced negative emotions such as anxiety, sadness and "just more despair" in response to the EEA findings. "It's more evidence, I know the things that I believe are true and this is more proof of that, but again, what can I do about it? ... it creates anxiety every time that instead of having a solution, I just have the problems like a list of things that are going wrong."

\section{Discussion}

Researchers have previously pointed out the potential public engagement value of EEA (e.g., Sippel et al. 2015; Messling et al. 2015; National Academies of Sciences Engineering and Medicine 2016). Our findings provide new empirical evidence in support of these claims, while also highlighting several communication challenges (Table 1). Overall, the focus group participants found EEA interesting, relevant, and attention grabbing. For many participants, it provided additional proof that climate change is happening now and a feeling of validation for their concerns. Participant statements indicate a process of sensemaking in response to extreme events, in which participants connected attribution findings to their personal experiences and observations of extreme weather, and in turn, perceived a stronger connection to climate change (Tisch and Galbreath 2018). Several participants described feeling a change in the weather and they interpreted EEA findings as scientific verification of these perceptions.

As described above, Lusk (2020) suggests that communicators focus on general relationships between climate change and extreme weather, rather than sharing a number on how a specific event was influenced by climate change because it could lead to scientific misunderstandings of causality. It remains unclear from our results to what extent participants fully understood the nuances of what attribution can and cannot say about the role of anthropogenic climate change in extreme events, so this remains a potential risk. Nevertheless, neglecting to utilize EEA 
TABLE 1. Key benefits and challenges of utilizing EEA results as a climate change communication and public engagement tool.

EEA benefits for public engagement

Resonates with individual experiences and/or observations of specific extreme weather events

Quantification of climate change impacts can grab attention and be persuasive

Comparing counterfactual worlds can be thought provoking and engage the imagination

Provides further compelling scientific evidence on the connections between extreme events and anthropogenic climate change
EEA challenges for public engagement

EEA's focus on hazards may detract from considerations of vulnerability, disaster risk reduction, and adaptation

Changing probabilities and likelihoods can be difficult to interpret; the magnitude of an EEA result may also influence responses

Scientific uncertainty can be difficult to communicate and may undermine accessibility of EEA results

Motivated reasoning can lead audiences to interpret EEA results through the lens of their preexisting ideologies in climate change communication campaigns could be a missed opportunity to call greater attention to the role of climate change in influencing specific weather events. According to our focus groups, EEA results are more engaging and persuasive than simply communicating general climate change and extreme weather relationships-which, as pointed out by one participant, has already been done for decades by scientists and activists. Participants felt that providing a specific number of how climate change influences extreme events offered an impression that the science was more robust and precise. It was also more attention grabbing. Several participants alluded to advertisements that cite statistics about a product's effectiveness to demonstrate its quality. The participants' appreciation of EEA's specificity helps explain why they reacted negatively to language that they felt watered down EEA findings with uncertainty ranges or academic jargon. Additionally, statements often found in media reporting such as "this is the sort of event which scientists say will become more common" (Painter et al. 2020; Betts 2021) may not resonate as strongly with readers as a specific number.

Many participants were interested in the counterfactual component of attribution (comparing models of the planet today vs a planet with a different level of anthropogenic greenhouse gas emissions). That the counterfactual component of EEA stuck out to participants mirrors decades of research in psychology around the importance of counterfactual thinking- "mental representations of alternatives to the past”' (Roese 1997, p. 133) —as part of human cognition (Kahneman and Tversky 1982). Reflecting on alternate versions of reality enables individuals to consider the causal impacts of prior choices, "what if" questions, which can be useful for guiding future decisions. EEA seems capable of activating this cognitive process in the context of anthropogenic climate change.

On the other hand, our findings highlight significant challenges associated with communicating EEA to nonclimate scientists. First, participants felt that EEA results can be difficult to interpret without training in climate science or strong numeracy skills (Painter 2013). Furthermore, many participants pointed out how their personal backgrounds shaped their responses to the data, which could limit generalizations concerning how diverse individuals would respond to EEA. Participants also acknowledged how they interpreted EEA based on their preexisting beliefs about climate change. This aligns with prior research demonstrating how individuals can engage in motivated reasoning of EEA results
(Osaka and Bellamy 2020), hold diverse cultural constructions of climate and weather (Hulme 2017), and filter information through contextual subjective ideologies (Moser 2016; Maeseele and Pepermans 2017).

Crucially, we found significant evidence of a related concern about the way EEA results are often framed in communications: that focusing exclusively on natural hazards could detract from considerations of other crucial components of extreme events, including vulnerability, exposure, adaptation, and disaster risk reduction (Hulme et al. 2011). It was striking that no participants made any distinctions between changing meteorological risks of extreme weather and steps that can be taken to reduce vulnerability to these events. Greenhouse gas mitigation is only part of the story of resilience to extreme weather risks. Importantly, we did not raise this point as part of our focus group materials in order to examine if participants independently considered these nuances around extreme events, which they did not whatsoever. This is not a flaw inherent to EEA itself; as we note in our communication guidelines below, such misunderstandings can be reduced or avoided through careful messaging strategies that seek to provide a more holistic view of extreme weather risks and vulnerability.

With regard to communication strategies, participants unanimously agreed that the words used to communicate EEA mattered a great deal, which underscores the need for standardized language (Lewis et al. 2019). Participants emphasized the importance of using everyday, simple phrases wherever possible to describe EEA results, which supports the recommendations of Hassol et al. (2016) and Budimir and Brown (2017). Many participants felt that pairing EEA findings with local stories and human impacts would boost the effectiveness of EEA for climate change engagement. Their emphasis on storytelling reflects the importance of narratives around extreme weather and climate change (Marshall 2014; Ettinger et al. 2021). EEA results should be made personally relevant to individuals and their experiences-according to our participants, numbers alone are less likely to have a memorable and meaningful impact on climate change engagement. Recent research has found that telling personal stories of harm can be effective for engaging members of the public about societal issues across political and ideological divides (Kubin et al. 2021).

All participants supported using visuals to communicate EEA, which they felt helped express EEA results more effectively. However, it is clear from our results that visuals need 
to be used with significant caution. Participants expressed a wide range of reactions to specific details of the visuals, including the iconography, colors, direction of charts and amount of text alongside the diagrams. As described above, they reacted positively to a gauge visual because of its familiarity but urged caution in its use because of the confusing colors and scale, whereas a boxplot taken directly from an academic publication was perceived extremely negatively. Our results therefore support the conclusions of Budimir and Brown (2017) that visuals can be useful learning aids for EEA but require careful utilization to ensure the proper message is conveyed.

It was notable that all participants were adamant that the communication of scientific uncertainty associated with EEA findings was unnecessary and even detrimental in terms of accessibility and engagement. This sentiment aligns with participants' views that EEA should be communicated as simply as possible and for maximum clarity. Participants generally understood that uncertainty was inherent to science, but they felt it made EEA more challenging to understand without relevant expertise. Some recent studies have found that expressing uncertainty can increase or have no effect on public trust in science (L. C. Howe et al. 2019; van der Bles et al. 2020). Nevertheless, the strong views among participants against the inclusion of uncertainty raises questions on how this information can be expressed without undermining the accessibility of key EEA conclusions. Perhaps, like the communication of health safety behaviors during the coronavirus pandemic, situating EEA in the context of risk management frameworks could potentially help participants understand how particular behavioral interventions can mitigate risks despite inherent uncertainties (Pidgeon 2012; Painter 2013).

\section{a. Implications for public engagement with climate change}

It is crucial to consider our findings in light of welldocumented flaws associated with the information deficit model of science communication-the notion that the provision of scientific information can remedy gaps in public knowledge (Sturgis and Allum 2004). As described above, a variety of sociocultural and psychological mechanisms shape how the public engages with information. Therefore, based on our results and with acknowledgment of these complex dynamics, we view EEA as a useful, attention-grabbing tool to help catalyze and inform dialogues about the relationships between climate change and extreme events, opening a door for further engagement on this issue and perhaps increased support for climate action. It is also worth mentioning that about half of our participants reported negative emotional responses to the EEA materials, such as sadness and despair. This highlights the importance of including solutions in climate messages in order to avoid apathy and support feelings of efficacy to fight climate change (Hart and Feldman 2016).

\section{b. Study limitations and directions for future research}

As a focus group study, our sample size is not statistically representative of the U.K. population. Given limitations of our focus group methodology, we cannot claim whether EEA can directly influence public attitudes or behaviors in response to climate change. All participants were also highly concerned about climate change prior to participating, so we cannot make any claims about the potential ability of EEA to reach skeptical audiences. Beyond sample characteristics, opinions expressed in a research focus group may differ from how participants would react to EEA in a nonexperimental context. Additionally, only one EEA study was utilized to test communication options-different weather events and different attribution results may be perceived differently.

This exploratory study offers several promising directions for future research, especially through methods involving a greater number of participants than a focus group can permit. For instance, can EEA results help raise climate concerns among audiences disengaged or skeptical about climate change? How do audiences respond to EEA results that find no anthropogenic influence on the likelihood or intensity of an extreme event? Continued research into communications aspects of EEA would provide more valuable insights on how to make EEA results accessible beyond the climate science community.

\section{Conclusions}

EEA shows considerable promise as a climate change communication tool because of its ability to provide novel, engaging and precise scientific information connecting specific extreme weather events to climate change. Its attentiongrabbing results could prove useful as a way of sparking dialogues about the relationship between different kinds of extreme weather events and anthropogenic climate change. Major communication challenges include adequately conveying nuances about the roles of climate change mitigation and adaptation in shaping risks associated with extreme weather events, expressing scientific uncertainty without undermining the accessibility of key findings, and overcoming numeracy difficulties among audiences to interpret EEA results. We offer the following recommendations for communicating EEA beyond the climate science community.

\section{a. Center messages around vulnerability}

Communicators should focus their messages on the concept of vulnerability to extreme weather and through this lens, incorporate the roles of climate change (including EEA results) and other dynamics that shape risks, such as exposure, adaptation, disaster risk reduction and community preparedness. This will help clarify that EEA results demonstrate the changing likelihood/intensity of natural hazards and how mitigation can address the meteorological component of extreme events, alongside other important ways societal decision-making and planning can reduce risks. Additionally, centering messages around vulnerability helps incorporate tangible, on-the-ground impacts and stories associated with these events, reminding audiences why this topic is crucially important for human well-being.

\section{b. Communicate using everyday language}

Language used to communicate EEA to the public should be simple, concise and avoid technical and academic jargon 
(Hassol et al. 2016). Words such as "likelihood," "intensity," and "frequency" are more relatable than terms such as "probability," "magnitude," and "return time." Our results show that communicating scientific uncertainty can be a challenge for public engagement with EEA. One strategy to provide this information in the EEA context is to "lead with what is known" rather than beginning a message with uncertainties and limitations (Somerville and Hassol 2011; Hassol et al. 2016, p. 8). Messages can also seek to reinforce an audience's understanding of probabilities and uncertainty by emphasizing how they regularly make decisions under conditions of uncertainty (e.g., choosing an outfit to wear based on a weather forecast). Furthermore, instead of describing uncertainty as an obstacle to understanding, communicators could seek to reframe it as an opportunity to engage the public on how the scientific process works and build credibility through transparency (van der Bles et al. 2020).

\section{c. Use familiar and evocative visuals}

Our results support the usage of visuals such as simple scales, gauges, and iconography that are already familiar to public audiences. More technical data visualizations taken directly from scientific publications could be confusing and disengaging to those without appropriate expertise to interpret them. Imagery that evokes the severity of extreme weather through the strategic use of color, size, and content can make a message more engaging. Pilot testing visuals with target audiences can help ensure they convey intended messages.

\section{d. Emphasize the counterfactual aspect of EEA}

Counterfactual thinking, that is, the imagination of alternate realities, is an important part of human cognition. Therefore, the counterfactual component of EEA methodologies can be compelling to audiences. By emphasizing the role of counterfactuals in EEA studies-modeling virtual worlds with different levels of anthropogenic greenhouse gas emissionsscientists and communicators can demonstrate the impacts of prior societal decisions on today's environment and how our decisions now shape future risks. It is key that communicators emphasize that these models can never perfectly construct the world; they can nevertheless be useful for considering alternate possibilities and guiding decision-making.

With a careful communication approach, EEA could prove a valuable resource for those seeking to engage the public about the risks of climate change and help facilitate "teachable moments" in the wake of extreme weather events. In particular, focusing solely on the meteorological hazard, without highlighting the roles of vulnerability and exposure in shaping disasters, offers audiences an important but incomplete perspective of how humanity can chart a safer and more resilient future.

Acknowledgments. We express our gratitude to our focus group participants for their support of this research during the challenging time of the coronavirus. We also thank Stephanie Ferguson of the Oxford University Environmental Change Institute for additional support with the visual components of this study, as well as this paper's reviewers and editors for their helpful feedback. This work was supported by a grant from the Royal Bank of Canada.

Data availability statement. The materials utilized in this study and the content analysis codes are available for reference in the online supplemental material.

\section{REFERENCES}

Akerlof, K., E. W. Maibach, D. Fitzgerald, A. Y. Cedeno, and A. Neuman, 2013: Do people "personally experience" global warming, and if so how, and does it matter? Global Environ. Change, 23, 81-91, https://doi.org/10.1016/j.gloenvcha.2012.07.006.

Albright, E. A., and D. A. Crow, 2015: Learning in the aftermath of extreme floods: Community damage and stakeholder perceptions of future risk. Risks Hazards Crisis Public Policy, 6, 308-328, https://doi.org/10.1002/rhc3.12085.

Allen, M., 2003: Liability for climate change. Nature, 421, 891-892, https://doi.org/10.1038/421891a.

Bar-Anan, Y., N. Liberman, and Y. Trope, 2006: The association between psychological distance and construal level: Evidence from an implicit association test. J. Exp. Psychol., 135, 609-622, https://doi.org/10.1037/0096-3445.135.4.609.

Bengtsson, M., 2016: How to plan and perform a qualitative study using content analysis. NursingPlus Open, 2, 8-14, https:// doi.org/10.1016/j.npls.2016.01.001.

Betts, R. A., 2021: Heed blame for extreme weather. Nature, 589, 493, https://doi.org/10.1038/d41586-021-00185-x.

Bloor, M., J. Frankland, K. Stewart, M. Thomas, and K. Robson, 2001: Focus Groups in Social Research. SAGE, 124 pp.

Borick, C. P., and B. G. Rabe, 2017: Personal experience, extreme weather events, and perceptions of climate change. Oxford Research Encyclopedia of Climate Science, Oxford University Press, https://doi.org/10.1093/acrefore/9780190228620.013.311.

Boudet, H., L. Giordono, C. Zanocco, H. Satein, and H. Whitley, 2020: Event attribution and partisanship shape local discussion of climate change after extreme weather. Nat. Climate Change, 10, 69-76, https://doi.org/10.1038/s41558-019-0641-3.

Budimir, D. M., and S. Brown, 2017: Communicating extreme weather event attribution: Research from India and Kenya. Practical Action Rep., 96 pp., https://cdkn.org/wp-content/ uploads/2017/06/Communicating-extreme-weather-eventattribution-FULL-REPORT.pdf.

Capstick, S., and Coauthors, 2019: Public opinion in a time of climate emergency. CAST Briefing Paper 2, 7 pp., https:// cast.ac.uk/wp-content/uploads/2020/01/CAST-Briefing-paper02-Pubic-opinion-in-a-time-of-climate-emergency-min.pdf.

Chmutina, K., and J. von Meding, 2019: A dilemma of language: "Natural disasters" in academic literature. Int. J. Disaster Risk Sci., 10, 283-292, https://doi.org/10.1007/s13753-019-00232-2.

Ciavarella, A., and Coauthors, 2020: Prolonged Siberian heat of 2020. World Weather Attribution Doc., 35 pp., https:// www.worldweatherattribution.org/wp-content/uploads/WWAProlonged-heat-Siberia-2020.pdf.

Copernicus, 2019: Prototype extreme events and attribution service. Accessed 7 October 2020, https://climate.copernicus.eu/ c3s62-prototype-extreme-events-and-attribution-service.

Demski, C., S. Capstick, N. Pidgeon, R. G. Sposato, and A. Spence, 2017: Experience of extreme weather affects climate change mitigation and adaptation responses. Climatic Change, 140, 149-164, https://doi.org/10.1007/s10584-016-1837-4.

Dixon, G., O. Bullock, and D. Adams, 2019: Unintended effects of emphasizing the role of climate change in recent natural 
disasters. Environ. Commun., 13, 135-143, https://doi.org/ 10.1080/17524032.2018.1546202.

Dryden, R., and M. G. Morgan, 2020: A simple strategy to communicate about climate attribution. Bull. Amer. Meteor. Soc., 101, E949-E953, https://doi.org/10.1175/BAMS-D-19-0174.1.

Earthjustice, 2019: How climate change is fueling extreme weather. Earthjustice, accessed 17 June 2020, https://earthjustice.org/ blog/2019-july/how-climate-change-is-fueling-extremeweather.

Easterling, D. R., K. E. Kunkel, M. F. Wehner, and L. Sun, 2016: Detection and attribution of climate extremes in the observed record. Wea. Climate Extremes, 11, 17-27, https://doi.org/ 10.1016/j.wace.2016.01.001.

Endfield, G. H., and L. Veale, 2018: Cultural Histories, Memories and Extreme Weather: A Historical Geography Perspective. Routledge, $174 \mathrm{pp}$.

Ettinger, J., F. E. L. Otto, and E. L. F. Schipper, 2021: Storytelling can be a powerful tool for science. Nature, 589, 352, https:// doi.org/10.1038/d41586-021-00108-w.

Feygina, I., T. Myers, B. Placky, S. Sublette, T. Souza, J. TooheyMorales, and E. Maibach, 2020: Localized climate reporting by TV weathercasters enhances public understanding of climate change as a local problem: Evidence from a randomized controlled experiment. Bull. Amer. Meteor. Soc., 101, E1092E1100, https://doi.org/10.1175/BAMS-D-19-0079.1.

Halperin, A., and P. Walton, 2018: The importance of place in communicating climate change to different facets of the American public. Wea. Climate Soc., 10, 291-305, https:// doi.org/10.1175/WCAS-D-16-0119.1.

Hamblyn, R., 2009: The whistleblower and the canary: Rhetorical constructions of climate change. J. Hist. Geogr., 35, 223-236, https://doi.org/10.1016/j.jhg.2008.09.006.

Hamilton, L. C., and M. D. Stampone, 2013: Blowin' in the wind: Short-term weather and belief in anthropogenic climate change. Wea. Climate Soc., 5, 112-119, https://doi.org/10.1175/ WCAS-D-12-00048.1.

Hansen, J., M. Sato, and R. Ruedy, 2012: Perception of climate change. Proc. Natl. Acad. Sci. USA, 109, E2415-E2423, https:// doi.org/10.1073/pnas.1205276109.

Hart, P. S., and L. Feldman, 2016: The influence of climate change efficacy messages and efficacy beliefs on intended political participation. PLOS ONE, 11, e0157658, https://doi.org/10.1371/ journal.pone.0157658.

Hassol, S. J., S. Torok, S. Lewis, and P. Luganda, 2016: Natural disasters: Communicating linkages between extreme events and climate change. WMO Bull., 65, 2-9.

Hazlett, C., and M. Mildenberger, 2020: Wildfire exposure increases pro-environment voting within Democratic but not Republican areas. Amer. Polit. Sci. Rev., 114, 1359-1365, https://doi.org/10.1017/S0003055420000441.

Howe, L. C., B. MacInnis, J. A. Krosnick, E. M. Markowitz, and R. Socolow, 2019: Acknowledging uncertainty impacts public acceptance of climate scientists' predictions. Nat. Climate Change, 9, 863-867, https://doi.org/10.1038/s41558-019-0587-5.

Howe, P. D., J. R. Marlon, M. Mildenberger, and B. S. Shield, 2019: How will climate change shape climate opinion? Environ. Res. Lett., 14, 113001, https://doi.org/10.1088/1748-9326/ab466a.

Hulme, M., 2017: Weathered: Cultures of Climate. SAGE, 201 pp.

— S. J. O'Neill, and S. Dessai, 2011: Is weather event attribution necessary for adaptation funding? Science, 334, 764-765, https://doi.org/10.1126/science.1211740.

IPCC, 2018: Summary for policymakers. Global Warming of $1.5^{\circ} \mathrm{C}$, V. Masson-Delmotte et al., Eds., Cambridge University Press,
1-24, https://www.ipcc.ch/site/assets/uploads/sites/2/2019/05/ SR15_SPM_version_report_LR.pdf.

Jackson, G., 2017: Conversation's last refuge: The art, and heart, of talking about the weather. Guardian, 20 February 2017, https://www.theguardian.com/commentisfree/2017/feb/20/ conversations-last-refuge-the-art-and-heart-of-talking-aboutthe-weather.

James, R., F. Otto, H. Parker, E. Boyd, R. Cornforth, D. Mitchell, and M. Allen, 2014: Characterizing loss and damage from climate change. Nat. Climate Change, 4, 938-939, https:// doi.org/10.1038/nclimate2411.

Janković, V., and D. M. Schultz, 2017: Atmosfear: Communicating the effects of climate change on extreme weather. Wea. Climate Soc., 9, 27-37, https://doi.org/10.1175/WCAS-D-160030.1.

Jones, C., D. W. Hine, and A. D. G. Marks, 2017: The future is now: Reducing psychological distance to increase public engagement with climate change. Risk Anal., 37, 331-341, https:// doi.org/10.1111/risa.12601.

Kahneman, D., and A. Tversky, 1982: The simulation heuristic. Judgment under Uncertainty: Heuristics and Biases, D. Kahneman, P. Slovic, and Tversky, Eds., Cambridge University Press, 201-208.

Kasperson, R. E., O. Renn, P. Slovic, H. S. Brown, J. Emel, R. Goble, J. X. Kasperson, and S. Ratick, 1988: The social amplification of risk: A conceptual framework. Risk Anal., 8, 177-187, https://doi.org/10.1111/j.1539-6924.1988.tb01168.x.

Kelman, I., 2020: Disaster by Choice: How Our Actions Turn Natural Hazards into Catastrophes. Oxford University Press, $180 \mathrm{pp}$.

Konisky, D. M., L. Hughes, and C. H. Kaylor, 2016: Extreme weather events and climate change concern. Climatic Change, 134, 533-547, https://doi.org/10.1007/s10584-015-1555-3.

Krueger, R., and M. A. Casey, 2000: Focus Groups: A Practical Guide for Applied Research. SAGE, 241 pp.

Kubin, E., C. Puryear, C. Schein, and K. Gray, 2021: Personal experiences bridge moral and political divides better than facts. Proc. Natl. Acad. Sci. USA, 118, e2008389118, https://doi.org/ 10.1073/pnas.2008389118.

Lahsen, M., G. A. Couto, and I. Lorenzoni, 2020: When climate change is not blamed: The politics of disaster attribution in international perspective. Climatic Change, 158, 213-233, https://doi.org/10.1007/s10584-019-02642-z.

Leiserowitz, A., and Coauthors, 2020: Climate Change in the American Mind: April 2020. Yale University and George Mason University Yale Program on Climate Change Communication Doc., 117 pp., https://climatecommunication.yale.edu/wpcontent/uploads/2020/05/climate-change-american-mindapril-2020b.pdf.

Lewis, S. C., A. D. King, S. E. Perkins-Kirkpatrick, and M. F. Wehner, 2019: Toward calibrated language for effectively communicating the results of extreme event attribution studies. Earth's Future, 7, 1020-1026, https://doi.org/10.1029/ 2019EF001273.

Li, Y., E. J. Johnson, and L. Zaval, 2011: Local warming: Daily temperature change influences belief in global warming. Psychol. Sci., 22, 454-459, https://doi.org/10.1177/ 0956797611400913.

Lusk, G., 2020: Should individual extreme weather events be attributed to human agency? Contemporary Climate Change Debates: A Student Primer, M. Hulme, Eds., Routledge, 42-50.

Maeseele, P., and Y. Pepermans, 2017: Ideology in climate change communication. Oxford Research Encyclopedia of Climate 
Science, Oxford University Press, https://doi.org/10.1093/ acrefore/9780190228620.013.578.

Maibach, E., B. W. Placky, J. Witte, K. Seitter, N. Gardiner, T. Myers, S. Sublette, and H. Cullen, 2016: TV meteorologists as local climate change educators. Oxford Research Encyclopedia of Climate Science, Oxford University Press, https://doi.org/10.1093/acrefore/9780190228620.013.505.

Marjanac, S., L. Patton, and J. Thornton, 2017: Acts of God, human influence and litigation. Nat. Geosci., 10, 616-619, https:// doi.org/10.1038/ngeo3019.

Marshall, G., 2014: Extreme weather and climate after the floods: Communicating climate change around extreme weather. Climate Outreach, accessed 8 October 2020, https://climateoutreach.org/reports/communicating-climatechange-around-recent-extreme-weather-events/.

Massumi, B., 2011: The half-life of disaster. Guardian, 15 April 2011, https:/www.theguardian.com/commentisfree/2011/apr/ 15/half-life-of-disaster.

Messling, L., A. Corner, J. Clarke, N. F. Pidgeon, C. Demski, and S. Capstick, 2015: Communicating flood risks in a changing climate. Climate Outreach Doc., 26 pp., https://climateaccess.org/ system/files/COIN_Flood\%20Risk.pdf.

Mildenberger, M., and A. Leiserowitz, 2017: Public opinion on climate change: Is there an economy-environment tradeoff? Env. Polit., 26, 801-824, https://doi.org/10.1080/ 09644016.2017.1322275.

Minnerop, P., and F. Otto, 2020: Climate change and causation. Joining law and climate science on the basis of formal logic. Buffalo Environ. Law J., 27, 49-86, https://doi.org/10.2139/ ssrn.3522519.

Morgan, D. L., 1996: Focus Groups as Qualitative Research. SAGE, $92 \mathrm{pp}$.

Moser, S. C., 2016: Reflections on climate change communication research and practice in the second decade of the 21st century: What more is there to say? Wiley Interdiscip. Rev.: Climate Change, 7, 345-369, https://doi.org/10.1002/wcc.403.

National Academies of Sciences, Engineering, and Medicine, 2016: Attribution of Extreme Weather Events in the Context of Climate Change. National Academies Press, $187 \mathrm{pp}$.

Ogunbode, C. A., C. Demski, S. B. Capstick, and R. G. Sposato, 2019: Attribution matters: Revisiting the link between extreme weather experience and climate change mitigation responses. Global Environ. Change, 54, 31-39, https://doi.org/ 10.1016/j.gloenvcha.2018.11.005.

Osaka, S., and R. Bellamy, 2020: Natural variability or climate change? Stakeholder and citizen perceptions of extreme event attribution. Global Environ. Change, 62, 102070, https:// doi.org/10.1016/j.gloenvcha.2020.102070.

_ sentation of extreme event attribution: A case study of the 2011-17 California drought. Wea. Climate Soc., 12, 847-862, https://doi.org/10.1175/WCAS-D-19-0050.1.

Otto, F. E. L., 2017: Attribution of weather and climate events. Annu. Rev. Environ. Resour., 42, 627-646, https://doi.org/ 10.1146/annurev-environ-102016-060847.

- - and Coauthors, 2020: Challenges to understanding extreme weather changes in lower income countries. Bull. Amer. Meteor. Soc., 101, E1851-E1860, https://doi.org/10.1175/ BAMS-D-19-0317.1.

Painter, J., 2013: Climate Change in the Media: Reporting Risk and Uncertainty. University of Oxford, 192 pp.

__ and S. J. Hassol, 2020: Reporting extreme weather events. Research Handbook on Communicating Climate Change,
D. C. Holmes and L. M. Richardson, Eds., Edward Elgar, 183-195.

— S. Osaka, J. Ettinger, and P. Walton, 2020: Blaming climate change? How Indian mainstream media covered two extreme weather events in 2015. Global Environ. Change, 63, 102119, https://doi.org/10.1016/j.gloenvcha.2020.102119.

Parker, H. R., and Coauthors, 2016: Using a game to engage stakeholders in extreme event attribution science. Int. J. Disaster Risk Sci., 7, 353-365, https://doi.org/10.1007/ s13753-016-0105-6.

Pidcock, R., R. Pearce, and R. McSweeney, 2020: Mapped: How climate change affects extreme weather around the world. Carbon Brief, accessed 7 October 2020, https:// www.carbonbrief.org/mapped-how-climate-change-affectsextreme-weather-around-the-world.

Pidgeon, N., 2012: Public understanding of, and attitudes to, climate change: UK and international perspectives and policy. Climate Policy, 12, S85-S106, https://doi.org/10.1080/ 14693062.2012.702982.

Redelmeier, D. A., and K. Ng, 2020: Approach to making the availability heuristic less available. BMJ Qual. Saf., 29, 528-530, https://doi.org/10.1136/bmjqs-2020-010831.

Reser, J. P., G. L. Bradley, and M. C. Ellul, 2014: Encountering climate change: 'Seeing' is more than 'believing.' Wiley Interdiscip. Rev.: Climate Change, 5, 521-537, https://doi.org/ 10.1002/wcc. 286

Roese, N. J., 1997: Counterfactual thinking. Psychol. Bull., 121, 133-148, https://doi.org/10.1037/0033-2909.121.1.133.

Rudiak-Gould, P., 2013: "We have seen it with our own eyes": Why we disagree about climate change visibility. Wea. Climate Soc., 5, 120-132, https://doi.org/10.1175/WCAS-D-12-00034.1.

Sarewitz, D., 2011: Does climate change knowledge really matter? Wiley Interdiscip. Rev.: Climate Change, 2, 475-481, https:// doi.org/10.1002/WCC.126.

Schwartz, J., 2019: Global warming concerns rise among Americans in new poll. New York Times, accessed 22 January 2019, https:// www.nytimes.com/2019/01/22/climate/americans-global-warmingpoll.html.

Sippel, S., P. Walton, and F. E. L. Otto, 2015: Stakeholder perspectives on the attribution of extreme weather events: An explorative enquiry. Wea. Climate Soc., 7, 224-237, https:// doi.org/10.1175/WCAS-D-14-00045.1.

Smith, A., and K. Jenkins, 2013: Climate change and extreme weather in the USA: Discourse analysis and strategies for an emerging 'public.' J. Environ. Stud. Sci., 3, 259-268, https:// doi.org/10.1007/s13412-013-0132-1.

Somerville, R. C. J., and S. J. Hassol, 2011: Communicating the science of climate change. Phys. Today, 64, 48-53, https:// doi.org/10.1063/PT.3.1296.

Spence, A., W. Poortinga, C. Butler, and N. F. Pidgeon, 2011: Perceptions of climate change and willingness to save energy related to flood experience. Nat. Climate Change, 1, 46-49, https://doi.org/10.1038/nclimate1059.

Stott, P. A., and P. Walton, 2013: Attribution of climate-related events: Understanding stakeholder needs. Weather, 68, 274-279, https://doi.org/10.1002/wea.2141.

Sturgis, P., and N. Allum, 2004: Science in society: Re-evaluating the deficit model of public attitudes. Public Understanding Sci., 13, 55-74, https://doi.org/10.1177/0963662504042690.

Sun, Y., and Z. Han, 2018: Climate change risk perception in Taiwan: Correlation with individual and societal factors. Int. J. Environ. Res. Public Health, 15, 91, https://doi.org/10.3390/ ijerph15010091. 
Tisch, D., and J. Galbreath, 2018: Building organizational resilience through sensemaking: The case of climate change and extreme weather events. Bus. Strategy Environ., 27, 1197-1208, https:// doi.org/10.1002/bse.2062.

van der Bles, A. M., S. van der Linden, A. L. J. Freeman, and D. J. Spiegelhalter, 2020: The effects of communicating uncertainty on public trust in facts and numbers. Proc. Natl. Acad. Sci. USA, 117, 7672-7683, https://doi.org/10.1073/pnas.1913678117.

van der Linden, S., 2014: On the relationship between personal experience, affect and risk perception: The case of climate change. Eur. J. Soc. Psychol., 44, 430-440, https://doi.org/ 10.1002/ejsp.2008.

van Oldenborgh, G. J., and Coauthors, 2020. Attribution of the Australian bushfire risk to anthropogenic climate change. Nat. Hazards Earth Syst. Sci., 21, 941-960, https://doi.org/10.5194/ nhess-21-941-2021.

Vautard, R., and Coauthors, 2019: Human contribution to the record-breaking July 2019 heat wave in western Europe.
World Weather Attribution, accessed 8 February 2021, https:// www.worldweatherattribution.org/wp-content/uploads/ July2019heatwave.pdf.

Wallace, J. M., 2012: Weather- and climate-related extreme events: Teachable moments. Eos, Trans. Amer. Geophys. Union, 93, 120, https://doi.org/10.1029/2012EO110004.

Whitmarsh, L., 2008: Are flood victims more concerned about climate change than other people? The role of direct experience in risk perception and behavioural response. J. Risk Res., 11, 351-374, https://doi.org/10.1080/13669870701552235.

World Weather Attribution, 2020: About World Weather Attribution. Accessed 7 October 2020, https://www.worldweatherattribution.org/ about/.

Zanocco, C., H. Boudet, R. Nilson, and J. Flora, 2019: Personal harm and support for climate change mitigation policies: Evidence from 10 U.S. communities impacted by extreme weather. Global Environ. Change, 59, 101984, https://doi.org/ 10.1016/j.gloenvcha.2019.101984. 